\title{
Biochemical and proteomic analyses of the physiological response induced by individual housing in gilts provide new potential stress markers
}

Anna Marco-Ramell ${ }^{1,6}$, Laura Arroyo ${ }^{1}$, Raquel Peña ${ }^{1,2}$, Raquel Pato ${ }^{1,2}$, Yolanda Saco ${ }^{1,2}$, Lorenzo Fraile ${ }^{3,4}$, Emøke Bendixen ${ }^{5}$ and Anna Bassols ${ }^{1,2^{*}}$ (1)

\begin{abstract}
Background: The objective assessment of animal stress and welfare requires proper laboratory biomarkers. In this work, we have analyzed the changes in serum composition in gilts after switching their housing, from pen to individual stalls, which is generally accepted to cause animal discomfort.

Results: Blood and saliva samples were collected a day before and up to four days after changing the housing system. Biochemical analyses showed adaptive changes in lipid and protein metabolism after the housing switch, whereas cortisol and muscular markers showed a large variability between animals. 2D-DIGE and iTRAQ proteomic approaches revealed variations in serum protein composition after changing housing and diet of gilts. Both techniques showed alterations in two main homeostatic mechanisms: the innate immune and redox systems. The acute phase proteins haptoglobin, apolipoprotein A-I and a1-antichymotrypsin 3, and the antioxidant enzyme peroxiredoxin 2 were found differentially expressed by 2D-DIGE. Other proteins related to the innate immune system, including lactotransferrin, protegrin 3 and galectin 1 were also identified by iTRAQ, as well as oxidative stress enzymes such as peroxiredoxin 2 and glutathione peroxidase 3. Proteomics also revealed the decrease of apolipoproteins, and the presence of intracellular proteins in serum, which may indicate physical injury to tissues.

Conclusions: Housing of gilts in individual stalls and diet change increase lipid and protein catabolism, oxidative stress, activate the innate immune system and cause a certain degree of tissue damage. We propose that valuable assays for stress assessment in gilts may be based on a score composed by a combination of salivary cortisol, lipid metabolites, innate immunity and oxidative stress markers and intracellular proteins.
\end{abstract}

Keywords: Acute phase proteins, Biomarker, Individual confinement, Innate immunity, Lipids, Oxidative stress, Pig, Proteomics, Stress

\section{Background}

Sows have commonly been housed under field conditions in individual stalls throughout pregnancy because it eases animal handling, reduces social stress and allows appropriate feeding. This individual housing system has been considered to be stressful and harmful for animals

\footnotetext{
* Correspondence: anna.bassols@uab.cat

'Departament de Bioquímica i Biologia Molecular, Facultat de Veterinària, Universitat Autònoma de Barcelona, Cerdanyola del Vallès 08193, Spain ${ }^{2}$ Servei de Bioquímica Clínica Veterinària, Facultat de Veterinària, Universitat Autònoma de Barcelona, Cerdanyola del Vallès 08193, Spain

Full list of author information is available at the end of the article
}

by animal welfare experts [1] and consequently, this practice has been banned by the European Union (CD 2001/88/EC). In gestational stalls, sows have very limited space for moving or laying down $[2,3]$. As a consequence, skin abrasions, locomotion difficulties, and loss of muscle mass and bone resistance have been observed [4-6]. Moreover, abnormal behaviours [7] and reproductive problems [8,9] are more common in individual-housed sows than those housed in groups.

Despite the importance of the objective evaluation of stress, information on laboratorial biomarkers is scarce. 
Some articles have assessed the validity of phenotypic animal-based measures such as lameness or oral stereotypies to monitor the welfare of sows $[10,11]$. Several behavioral measures such as sham chewing or excessive drinking suggest that sows in stalls found the conditions less comfortable and reflected a heightened arousal that prevented them from lying down due to stress and frustration [12]. Nevertheless, contradictory results have been also observed, since others have found that the drinking frequency was higher in group-housed sows, although an agonistic behavior and sham chewing was higher in stalls [13].

Thus, despite the utility of behavioral measures, the availability of a set of objective and easily measurable laboratory parameters that may be combined as a "welfare score" would be an outstanding element to monitor welfare in farm animals. The complementarity of animal behavior, biochemistry, physiology and immunology together with the use of modern, high-throughput technologies should help to create a more comprehensive scientific basis for animal care and management [14].

Previous studies of our group have defined potential laboratory markers to evaluate stress in male pigs housed at different stocking densities [15] that are monitored in gilts housed under stress conditions in the present study. Our first objective was to evaluate the metabolic and hormonal markers under a housing switch in females. A selection of proteins related to the acute phase response (APP) and oxidative stress pathways were also included in the analysis. On the other hand, a second objective was to extend the application of gel-based (2D-DIGE) and gel-free (iTRAQ labelling) proteomic technologies to search for potential novel serum markers for stress.

\section{Methods}

\section{Experimental design}

Six-month old gilts (Landrace $\mathrm{x}$ Large White $\mathrm{x}$ Duroc) from Picber SA (Lleida, Spain) were used. The study began in the quarantine facility (Day 1 (D1)), where animals $(n=60)$ had been housed for a month, in groups of 10. The following day, all the gilts were moved simultaneously to individual stalls accomplishing all-in and all-out management by productive phase at the Seponts S.L. piglet production farm (Ponts, Lleida, Spain).

Gilts were fed ad libitum in the quarantine facility (D1) or received approximately $2.5 \mathrm{~kg}$ of feed in the individual stalls (feed composition shown in Table 1). Animals were vaccinated against skin diamond disease, swine influenza virus, Ausjezky disease and Mycoplasma hyopneumoniae with the following commercial vaccines: Parvosuin MR, Gripork and Auskipra (Hipra, Amer, Spain), and Stellamune Mycoplasma (Elanco, Greenfield, IN), respectively. The last vaccine was injected a week before the
Table 1 Calculated composition of the diets for gilts allocated in pen or individual stalls based on its feed composition and its average daily feed in each case

\begin{tabular}{lcc}
\hline Diet & Pen & Individual stalls \\
\hline DM, g/Kg & 896 & 900.7 \\
DM basis, g/Kg & & \\
$\quad$ Protein & 158 & 135 \\
$\quad$ Fat & 65 & 49.3 \\
Crude fiber & 53 & 91.8 \\
Ash & 60 & 69.6 \\
$\quad$ Nitrogen free extract & 560 & 555 \\
ME, MJ/kg & 12.8 & 11.5 \\
Feed intake, Kg DM/day & 2.5 & 2.5 \\
ME intake, MJ/day & 32 & 29 \\
\hline
\end{tabular}

study. Moreover, gilts received ivermectin to control the parasite load (Paramectin, Syva, León, Spain) three weeks before the study.

Two groups of animals from the original quarantine group $(n=60)$ were considered:

- Group 'HS': a group of animals $(n=15)$ were sampled at D1, D3, D4 and D5. These animals were subjected to two types of stress: individual Housing $(\mathrm{H})$ and repeated Sampling (S).

- Group 'H': three different subgroups of gilts were formed and sampled at D3 $(n=15), \mathrm{D} 4(n=15)$ or D5 $(n=15)$. These animals were only subjected to the stress induced by individual Housing $(\mathrm{H})$ and not to repeated sampling.

This design allowed us to distinguish the effect unleashed by change of housing from the stress induced by repeated sampling, without disturbing the all-in and allout management system of the farm. In this experimental design, parameters measured at D1 corresponded to basal levels.

The experiment was carried out in a piglet production farm under field conditions before the actual EU legislation against separate housing came into force. Treatment, housing and husbandry conditions conformed to the European Union Guidelines (The Council of the European Communities 1986 and directive 2010/63/EU, where applicable). The experiment received approval from the Ethical Committee for Animal Experimentation from the Universitat de Lleida (DAAM7684).

\section{Sample collection and preparation}

Gilts were sampled in the morning, from 9 to 11 a.m. Blood was collected by jugular venipuncture in tubes without anticoagulant (for serum) or with EDTA-K 3 (for erythrocyte lysate and deproteinized blood). Serum 
was obtained by centrifugation at $2000 \mathrm{~g}$ for $10 \mathrm{~min}$. Erythrocyte lysate was prepared after blood centrifugation, as described for serum, and the cellular pellet was washed with $0.9 \%(\mathrm{w} / \mathrm{v}) \mathrm{NaCl}$ and lysed with cold desionized water. Deproteinized blood was obtained by mixing blood with $5 \%(\mathrm{v} / \mathrm{v})$ metaphosphoric acid followed by centrifugation at $3000 \mathrm{~g}$ for $5 \mathrm{~min}$. Saliva samples were collected on Salivette ${ }^{\mathrm{Tm}}$ tubes (Sarstedt, Nümbrecht, Germany) by allowing the gilts to chew spontaneously the cotton swabs for 30-60 s without immobilization. Cotton swabs were centrifuged at $4000 \mathrm{~g}$ for $10 \mathrm{~min}$. All centrifugations were at room temperature. Supernatants were frozen at $-80{ }^{\circ} \mathrm{C}$ until analysis.

\section{Analytical parameters}

Serum non-esterified fatty acids (NEFAs), triglycerides and cholesterol were determined as markers of lipid metabolism. Serum total protein, urea and creatinine were determined as indicators of protein metabolism. The measurement of metabolic parameters was carried out with the analyzer Olympus AU400 (Olympus Diagnostica $\mathrm{GmbH}$, Dublin, Ireland). Technical details are given in Table 2. All parameters were analysed in duplicate.

\section{Immunoblotting}

The carbonyl protein content was detected by slot blot and serum apolipoprotein A-I (Apo A-I) by immunoblotting, as described by Marco-Ramell et al. [15, 16], respectively. A control sample was used in both immunoassays to compare results from different membranes. Ratios between samples and control protein bands were calculated.

\section{Proteomic analyses}

Proteome changes were studied in two parallel pipelines. Discovery proteome studies were performed on pooled serum samples representing D1, D3 and D5 by 2D-DIGE and iTRAQ.

\section{D-Differential gel electrophoresis (2D-DIGE) and spot identification by mass spectrometry (MS)}

Serum samples corresponding to D1 (basal level) and to D3 and D5 for both groups ( $\mathrm{H}$ and $\mathrm{HS}$ ) were pooled, obtaining five pools in total $(n=15 /$ pool $)$, and then desalted and quantified. Fifty $\mu \mathrm{g}$ protein was labelled with $\mathrm{Cy} 2, \mathrm{Cy} 3$ or Cy5 dyes (GE Healthcare, Buckinghamshire, UK) and subjected to a bidimensional electrophoresis on four IPG strips (pH 4-7, $24 \mathrm{~cm}$, GE Healthcare) followed by $12.5 \%$ SDS-PAGE, as described in [16]. The pooled D1 sample was labelled with Cy2 and used as internal standard in all four gels. Dye-swap was performed and samples were randomly paired, as described in Additional file 1. Image analysis and statistical quantification of relative protein abundance was performed with Progenesis Samespots (v2.0) (NonLinear Dynamics, Newcastle, UK). The spot intensity at D3 was compared with D1 intensity for both animal groups. Spots that met the criteria $p<0.05$

Table 2 List of analytical methods

\begin{tabular}{|c|c|c|c|}
\hline Biochemical parameter & Sample type & Method & Manufacturer \\
\hline NEFAs & Serum & NEFA-C reagent & Wako Chemicals GmbH (Neuss, Germany) \\
\hline Cholesterol & Serum & CHOP-PAP-method & $\begin{array}{l}\text { Olympus System Reagents (OSR) -Olympus } \\
\text { Diagnostica GmbH }\end{array}$ \\
\hline Triglycerides & Serum & GPO-PAP method & OSR \\
\hline Urea & Serum & GLDH method & OSR \\
\hline Creatinine & Serum & Jaffé method & OSR \\
\hline Total protein & Serum & Biuret method & OSR \\
\hline Creatine kinase (CK) & Serum & IFCC method & OSR \\
\hline Alanine aminotransferase (ALT) & Serum & IFCC method, without pyridoxal phospate & OSR \\
\hline Alkaline phosphatase (ALP) & Serum & IFCC method & OSR \\
\hline Haptoglobin & Serum & Phase Haptoglobin kit (colorimetric assay & Tridelta Ltd (County Kildare, Ireland) \\
\hline C-reactive protein $(C R P)^{a}$ & Serum & Immunoturbidimetric method & OSR (\#6147) \\
\hline Pig-MAP & Serum & ELISA & PigChamp ProEuropa (Segovia, Spain) \\
\hline Cortisol & Serum & ELISA & DRG Diagnostics (Marburg, Germany) \\
\hline Cortisol & Saliva & ELISA & DRG Diagnostics \\
\hline Glutathione peroxidase (GPx) & Erythrocyte lysate & Cumene Hydroperoxide (Ransel) & Randox Laboratories Ltd \\
\hline Superoxide dismutase (SOD) & Erythrocyte lysate & Xanthine oxidase (Ransod) & Randox Laboratories Ltd \\
\hline Total glutathione (tGSH) & Deproteinized blood & Glutathione Assay & Northwest (Vancouver, WA) \\
\hline
\end{tabular}

Validated for porcine samples [42] 
and fold-change $(\mathrm{FC}) \geq \pm 1.2$ (in $\mathrm{H}$ or $\mathrm{HS}$ groups) were selected for further mass spectrometry (MS) identification. Spots located near the gel borders and small or faint spots were excluded from protein identification. Protein identification and confirmation was performed on an Ultraflex TOF-TOF Instrument (Bruker, Bremen, Germany). The resulting final peak list was used for protein identification by peptide mass fingerprint. Mascot 2.2 (Matrix Science Ltd., London, U.K.) was used to search the Swiss-Prot (v55.4) database. Criterion for positive identification was a significant Mascot probability (score $>55, P<0.05$ ). When protein identification was not achieved, spots were analyzed by ion trap MS on an Esquire HCT Ultra IT mass spectrometer (Bruker, Bremen, Germany), coupled to a nanoHPLC system (Ultimate, LC Packings, Amsterdam, The Netherlands). MS/MS fragmentation (100-2800 m/z) was performed on the most intense ions. MS/MS spectra were searched as: 1.5 Da precursor mass tolerance, 0.5 Da fragment tolerance, 1 trypsin missed cleavage, Cys carbamidomethylation as fixed modification and Met oxidation as variable modification. A positive identification criterion was set as an individual Mascot score for each peptide MS/MS spectrum higher than the corresponding homology threshold score. Full details about the procedures are described in [16].

Isobaric tag for relative and absolute quantitation (iTRAQ) Pooled samples at D1 (basal level) and both groups ( $\mathrm{H}$ and $\mathrm{HS}$ ) at D3 and D5 (5 pools in total, $n=15 /$ pool) were used. Pooled samples were enriched with ProteoMiner $^{\mathrm{TM}}$ (Bio-Rad, Hercules, CA) as described in [16] and then desalted and quantified. ProteoMiner was used to decrease the complexity of serum proteome since iTRAQ requires relatively simple protein mixtures [17].

Proteins were reduced, alkylated and digested. $100 \mu \mathrm{g}$ peptides were differentially labeled with iTRAQ $^{\circ}$ Reagents (AB Sciex, Framingham, MA). An internal pool, formed by all the samples, was also labeled for further normalization. Peptides were combined and fractionated on a 3100 OFFGEL Fractionator (Agilent) prior to MS analysis.

$0.5 \mu \mathrm{g}$ peptides were separated on a nano-UPLC ACQUITY system (Symmetry C18 nanotrapping precolumn plus BEH Acquity nanocolumn, both from Waters, Milford, MA) and analyzed on a LTQ-Orbitrap Velos (Thermo Fisher Scientific, Waltham, MA). Peptides (300$1800 \mathrm{~m} / \mathrm{z}$ ) were analyzed in Data Dependent mode (mass scan $30.000 \mathrm{FWHM}$ at $400 \mathrm{~m} / \mathrm{z}$ ). The ten most abundant peptides ( $\geq 2000$ counts) from each scan were chosen and fragmented using high energy collision dissociation in a C-trap (nitrogen, normalized collision energy of 50\%). Fragments were analyzed at 7.500 FWHM at $400 \mathrm{~m} / \mathrm{z}$. Full MS scan was $250 \mathrm{~ms}$ (1 Microscan) and MS/MS $300 \mathrm{~ms}$ (2 microscans).
Raw data was analyzed with Xcalibur 2.1.0.1140 and protein identification and relative quantification with Proteome Discoverer (both from Thermo Fisher Scientific). Search parameters were: $10 \mathrm{ppm}$ precursor mass tolerance, $0.1 \mathrm{Da}$ fragment mass tolerance, two missed trypsin cleavages, Cys carbamidomethylation and Lys and N-term iTRAQ labelling as fixed modifications, Met oxidation, N-term acetylation and Tyr iTRAQ labelling as variable modifications, Mascot score $>30$ and 'Other mammalia' taxonomy.

The correction factor for each isobaric label, provided by the manufacturer, was applied and the intensity of each isobaric tag was normalized with the intensity of the internal pool. The average intensity of all the peptides from the same protein was calculated and normalized by mean-centering, and the ratio between the intensity of each isobaric tag (corresponding to D3 or D5) versus D1 (basal conditions) was calculated for each protein.

Two criteria were then used to select differential proteins. First, a FC $\geq \pm 1.2$ at D3 versus D1 was required, independently of the variation at D5. Then FC were normalized due to the presence of intracellular proteins released to the bloodstream that might affect the overall extracellular proteins levels: only proteins exhibiting a FC greater than the median FC for increased and decreased proteins were selected. Identifications with less than two unique peptides were excluded from the selection.

\section{Statistical analysis of biochemical data}

All statistical analyses were carried out using the SAS system V.9.1.3 (SAS institute Inc, Cary, NC, USA). For all biochemical analyses, the individual pig was used as the experimental unit. When not specified, the significance level $(\alpha)$ was set at 0.05 . A test to discard outliers was not performed. The variables included in the statistical analyses were continuous. Shapiro-Wilk and Levene tests were used to evaluate the normality of the distribution of the variables and the homogeneity of variances, respectively. A non-parametric (Wilcoxon test) was chosen to compare the results obtained for all the measured parameters between D1 (basal level) and the rest of the days for the $\mathrm{H}$ and $\mathrm{HS}$ groups. The effect of repeated sampling on the parameters was carried out using a non-parametric (Wilcoxon test) between $\mathrm{H}$ and $\mathrm{HS}$ groups.

\section{Results}

\section{General biochemical profiling}

The metabolic and the stress response after transition to individual stalls was evaluated by measuring several blood parameters. Results at D3, D4 and D5 were always compared with basal levels (D1) in H and HS groups. Differences between $\mathrm{H}$ and $\mathrm{HS}$ groups are also described. All statistical differences are reported in Table 3 and Figs. 1 and 2. 
Table 3 Serum concentration of compounds related to lipid and protein metabolism, enzyme activities and cortisol in serum and saliva in the HS and the $\mathrm{H}$ group throughout the experimental period (mean \pm SD)

\begin{tabular}{|c|c|c|c|c|c|}
\hline Parameter & D1 & D3 & D4 & D5 & Group \\
\hline \multirow[t]{2}{*}{$\overline{\mathrm{NEFAs}, \mathrm{mmol} / \mathrm{L}}$} & $0.08 \pm 0.06$ & $0.13 \pm 0.58^{*}$ & $0.08 \pm 0.04$ & $0.04 \pm 0.01^{b}$ & $\mathrm{H}$ \\
\hline & & $0.14 \pm 0.04^{* *}$ & $0.09 \pm 0.06$ & $0.08 \pm 0.04^{\mathrm{a}}$ & $\mathrm{HS}$ \\
\hline \multirow[t]{2}{*}{ Triglycerides, mg/dL } & $49 \pm 18$ & $48 \pm 15$ & $64 \pm 20^{*}$ & $70 \pm 23^{* *}$ & $\mathrm{H}$ \\
\hline & & $53 \pm 16$ & $58 \pm 21$ & $85 \pm 29^{* *}$ & $\mathrm{HS}$ \\
\hline \multirow[t]{2}{*}{ Total cholesterol, mg/dL } & $101 \pm 18$ & $116 \pm 63$ & $93 \pm 11$ & $99 \pm 29$ & $\mathrm{H}$ \\
\hline & & $138 \pm 46^{*}$ & $94 \pm 17$ & $114 \pm 39$ & $\mathrm{HS}$ \\
\hline \multirow[t]{2}{*}{ Urea, mg/dL } & $31.4 \pm 5.5$ & $36.4 \pm 5.2^{*}$ & $25.1 \pm 4.7^{* *}$ & $24.0 \pm 3.4^{* * *}$ & $\mathrm{H}$ \\
\hline & & $32.3 \pm 10.3^{*}$ & $22.5 \pm 3.6^{* * *}$ & $22.7 \pm 4.1^{* * *}$ & $\mathrm{HS}$ \\
\hline \multirow[t]{2}{*}{ Creatinine, mg/dL } & $1.66 \pm 0.22$ & $1.96 \pm 0.31^{* *}$ & $1.84 \pm 0.20^{* a}$ & $1.90 \pm 0.25^{*}$ & $\mathrm{H}$ \\
\hline & & $1.91 \pm 0.28^{*}$ & $1.64 \pm 0.19^{b}$ & $1.82 \pm 0.43$ & $\mathrm{HS}$ \\
\hline \multirow[t]{2}{*}{ Total protein, g/dL } & $7.66 \pm 0.32$ & $8.11 \pm 0.58^{*}$ & $8.14 \pm 0.41^{* *_{a}}$ & $7.97 \pm 0.31^{*}$ & $\mathrm{H}$ \\
\hline & & $7.86 \pm 0.38$ & $7.85 \pm 0.36^{b}$ & $7.75 \pm 0.42$ & $\mathrm{HS}$ \\
\hline \multirow[t]{2}{*}{$\mathrm{CK}, \mathrm{U} / \mathrm{mL}$} & $7.85 \pm 16.25$ & $10.22 \pm 13.32^{b}$ & $10.66 \pm 28.46$ & $2.98 \pm 3.58$ & $\mathrm{H}$ \\
\hline & & $90.14 \pm 125.14^{* a}$ & $11.96 \pm 21.39$ & $38.90 \pm 65.58$ & $\mathrm{HS}$ \\
\hline \multirow[t]{2}{*}{ ALT, U/L } & $65.4 \pm 126.6$ & $97.1 \pm 125.0$ & $63.3 \pm 37.1$ & $62.4 \pm 22.4$ & $\mathrm{H}$ \\
\hline & & $125.6 \pm 95.6^{*}$ & $65.1 \pm 11.5$ & $72.9 \pm 19.6$ & $\mathrm{HS}$ \\
\hline \multirow[t]{2}{*}{$A L P, U / L$} & $104.7 \pm 31.2$ & $134.9 \pm 60.3$ & $100.3 \pm 22.3$ & $116.6 \pm 26.2$ & $\mathrm{H}$ \\
\hline & & $107.6 \pm 42.8$ & $105.4 \pm 32.3$ & $98.3 \pm 31.3$ & $\mathrm{HS}$ \\
\hline \multirow[t]{2}{*}{ Serum cortisol, $\mu \mathrm{g} / \mathrm{dL}$} & $8.47 \pm 4.92$ & $5.56 \pm 2.86$ & $7.02 \pm 4.93$ & $5.08 \pm 4.17^{*}$ & $\mathrm{H}$ \\
\hline & & $7.22 \pm 6.08$ & $6.32 \pm 4.79$ & $6.49 \pm 5.10$ & $\mathrm{HS}$ \\
\hline \multirow[t]{2}{*}{ Salivary cortisol, ng/mL } & $6.53 \pm 4.69$ & $9.88 \pm 6.96$ & $9.80 \pm 6.01^{*}$ & $11.29 \pm 6.33^{* *}$ & $\mathrm{H}$ \\
\hline & & $25.01 \pm 42.28$ & $14.54 \pm 12.36^{*}$ & $12.02 \pm 9.88^{* *}$ & HS \\
\hline
\end{tabular}

a,b Within columns, means with a different superscript differed significantly $(P<0.05)$ between $\mathrm{H}$ and $\mathrm{HS}$ group

Asterisks show significant differences versus D1: ${ }^{*} P<0.05$, ${ }^{* *} P<0.01$, ${ }^{* *} P<0.001$

A transient increase in non-esterified fatty acids (NEFA) was observed at D3 in both groups that was rapidly normalized at D4. Triglycerides (TG) significantly increased at the end of the study (D4 and D5 versus D1) in both groups. No changes were observed in total cholesterol except an increase at D3 in the HS group. No differences were observed between $\mathrm{HS}$ and $\mathrm{H}$ groups for any lipid marker with the exception of NEFA at D5, which were lower in the $\mathrm{H}$ group.

Urea decreased at D4 and D5 in both groups. Creatinine increased at D3 in both groups, and at D4 and D5 only in $\mathrm{H}$ group. Serum total protein concentration increased after the transition to individual stalls at D3 and D4. No differences between $\mathrm{HS}$ and $\mathrm{H}$ groups were observed, except for creatinine and total protein at D4.

Creatine kinase (CK), alanine aminotransferase (ALT) and alkaline phosphatase (ALP) enzymatic activities were measured in serum as markers of muscular (CK and ALT) or hepatic damage (ALT and ALP). A high interindividual variability in CK and ALT activities was found, especially in the HS group at D3. An increase in CK at D3 was observed in the HS group.
Cortisol was determined in serum and saliva as stress marker. A great inter-individual variability in this parameter was observed, especially in saliva. No significant effect was observed due either to the change of housing or to the repeated sampling procedure.

\section{Innate immune system and oxidative stress defences monitoring}

Porcine APP levels showed changes throughout the study and different kinetics between $\mathrm{H}$ and HS groups (Fig. 1). Haptoglobin (Hp) slightly increased at D3 and normalized afterwards. C-reactive protein (CRP) increased at D3 and onwards only in the HS group, whereas Apo A-I only decreased at D3 in the same animal group. Pig-MAP decreased at D3 and onwards only in the $\mathrm{H}$ group. Differences between both groups were observed in Hp and Apo A-I at D3, and throughout all the study (D3, D4 and D5) in CRP and Pig-MAP levels.

Oxidative stress markers also showed different kinetics after the housing change and between $\mathrm{H}$ and HS groups (Fig. 2). In the $\mathrm{H}$ group, glutathione peroxidase activity (GPx) increased at D4, superoxide dismutase (SOD) 

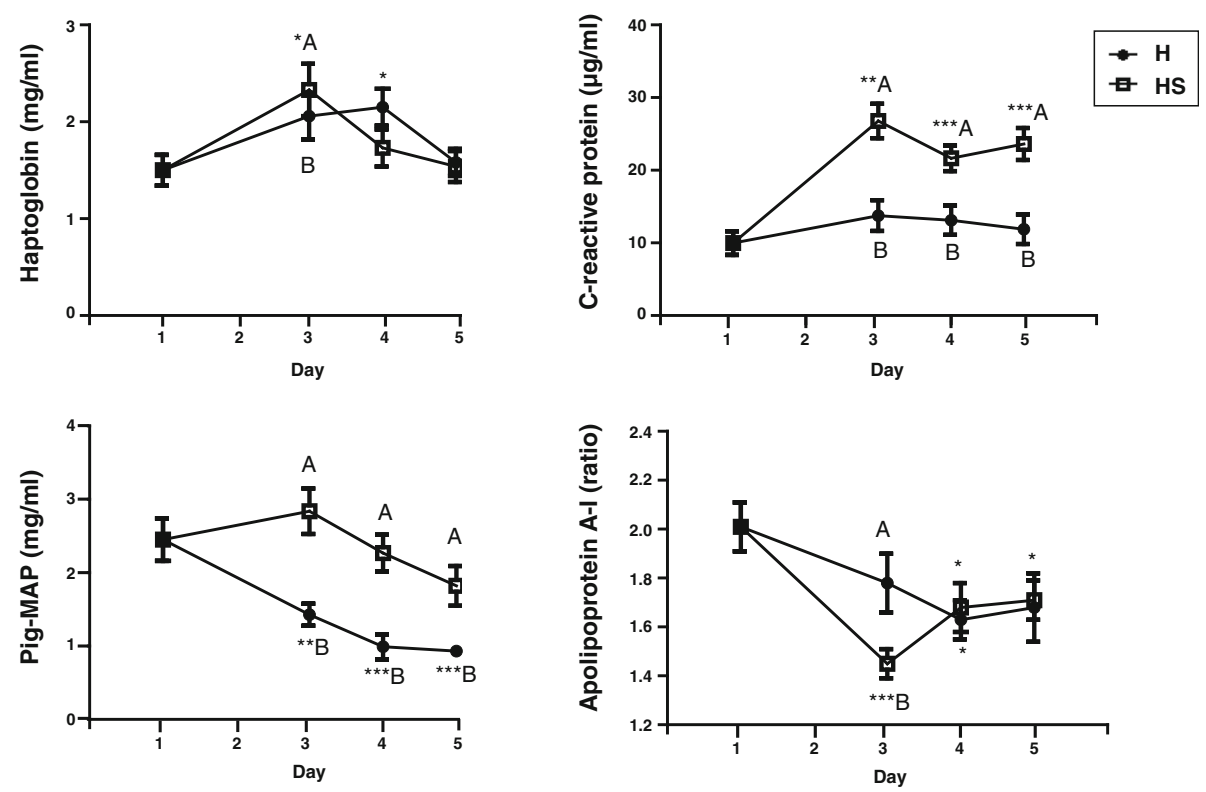

Fig. 1 Average serum concentrations of acute phase proteins in $\mathrm{H}$ and $\mathrm{HS}$ groups throughout the trial. Asterisks represent statistically significant differences between D3, D4 or D5 and basal levels (D1): ${ }^{*} P<0.05$, ${ }^{*} P<0.01$, ${ }^{* *} P<0.001$. Different letter means significant differences between $H$ and HS groups $(P<0.05)$

increased at D5, and slight increases were observed in tGSH and protein-carbonyl groups. Significant differences between HS and H groups were only observed for GPx at D4 and D5, and SOD at D5.

\section{Proteomic analysis}

Proteome changes were analyzed by 2D-DIGE and iTRAQ. Table 4 shows differentially expressed proteins at D3 and D5 versus D1 in the $\mathrm{H}$ and HS groups, identified by DIGE or iTRAQ. The complete list of identified proteins is shown in Additional file 2 (DIGE) and Additional file 3 (iTRAQ).

\section{D-DIGE}

A subset of 819 spots was found in all four bidimensional gels. Of these, 38 spots were differentially expressed. Ten of these were selected, as described in the Methods section, but only five of them could be identified by MS.
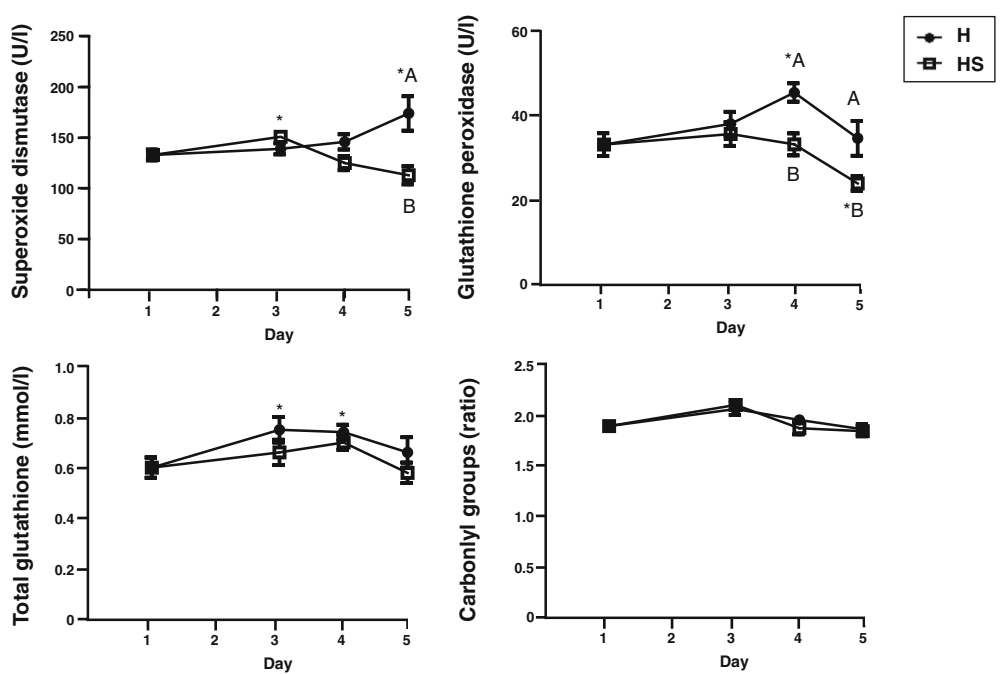

Fig. 2 Average serum concentrations of oxidative stress markers in $\mathrm{H}$ and $\mathrm{HS}$ groups throughout the trial. Asterisks represent statistically significant differences between D3, D4 or D5 and basal levels (D1): ${ }^{*} P<0.05,{ }^{* *} P<0.01$, ${ }^{* *} P<0.001$. Different letter means significant differences between $\mathrm{H}$ and HS groups $(P<0.05)$ 
Table 4 Selected differentially expressed proteins at D3 and D5 versus D1 (basal levels) in the H and HS groups identified by proteomics (DIGE or iTRAQ)

\begin{tabular}{|c|c|c|c|c|c|}
\hline \multirow[t]{2}{*}{ Protein } & \multirow[t]{2}{*}{ Technique } & \multicolumn{2}{|l|}{ Day 3} & \multicolumn{2}{|l|}{ Day 5} \\
\hline & & $\overline{\mathrm{FCH}}$ & $\overline{\mathrm{FCHS}}$ & $\mathrm{FCH}$ & $\mathrm{FC} \mathrm{HS}$ \\
\hline \multicolumn{6}{|l|}{ Immune system } \\
\hline Alpha-1- antichymotrypsin 3 & DIGE & 1.74 & 1.20 & 1.36 & 1.16 \\
\hline Galectin-1 & iTRAQ & 1.64 & 2.31 & 1.08 & 2.56 \\
\hline Haptoglobin (spot 1) & DIGE & 3.24 & 2.19 & 1.71 & 1.63 \\
\hline Haptoglobin (spot 2) & DIGE & 1.48 & 1.73 & 1.29 & 1.34 \\
\hline Lactotransferrin & iTRAQ & 1.21 & 1.38 & 1.54 & 1.08 \\
\hline Protegrin-3 & ITRAQ & 1.45 & 1.75 & 1.46 & 1.69 \\
\hline \multicolumn{6}{|l|}{ Transport } \\
\hline Apolipoprotein A-I & DIGE & -1.38 & -1.70 & -1.26 & -1.53 \\
\hline Apolipoprotein A-I & iTRAQ & -1.28 & -1.62 & -1.04 & -1.64 \\
\hline Apolipoprotein E & iTRAQ & -1.89 & -1.96 & -1.22 & -1.60 \\
\hline Apolipoprotein C-III & iTRAQ & -1.56 & -1.79 & -1.18 & -1.72 \\
\hline Apolipoprotein $\mathrm{R}$ & iTRAQ & -1.36 & -1.78 & -1.03 & -1.73 \\
\hline Apolipoprotein M & iTRAQ & -1.49 & -1.80 & -1.26 & -2.02 \\
\hline \multicolumn{6}{|l|}{ Antioxidant defenses } \\
\hline Glutathione peroxidase 3 & iTRAQ & -1.45 & -1.58 & -1.06 & -1.51 \\
\hline Peroxiredoxin 2 & DIGE & 3.73 & 5.78 & 2.09 & 4.86 \\
\hline Peroxiredoxin 2 & iTRAQ & 1.99 & 2.31 & 1.80 & 2.17 \\
\hline
\end{tabular}

Increased proteins at D3 are represented as positive fold-changes (FC) and decreased proteins as negative FC. Proteins are classified according to their biological function. The complete list of differentially expressed proteins identified by MS is shown in Additional file 1 (DIGE) and Additional file 2 (iTRAQ)

These identifications include the APP Hp (2 spots), Apo A-I and $\alpha 1$-antichymotrypsin 3 and the antioxidant enzyme peroxiredoxin 2 (PRDX2) (Fig. 3). Hp, $\alpha 1$ antichymotrypsin 3 and PRDX2 significantly increased whereas Apo A-I significantly decreased at D3 in $\mathrm{H}$ and HS groups. All four proteins tended to reach basal levels at D5 in both groups (Table 4).

\section{ITRAQ}

The 8-plex iTRAQ ${ }^{\circ}$ analysis yielded the identification of 262 proteins. The overall analysis of the data reflects a slight increase in intracellular proteins released to the bloodstream and a relative decrease in many extracellular proteins (Gene Ontology analysis, data not shown). To counteract this protein bias, iTRAQ data was normalized as described in the Methods section.

Sixty-seven decreased and 54 increased proteins at D3 met these two criteria (Additional file 3). Most proteins showed larger fold-change variations over time in the HS than the $\mathrm{H}$ group, and larger fold-change variations at D3 than at D5.

Amongst the differentially expressed proteins, two of them were common with the 2D-DIGE analysis: ApoA-I was found to be decreased and PRDX2 increased at D3 and D5. Other functionally-related proteins such as apolipoproteins C-III, E, M and R (lipid transport) and

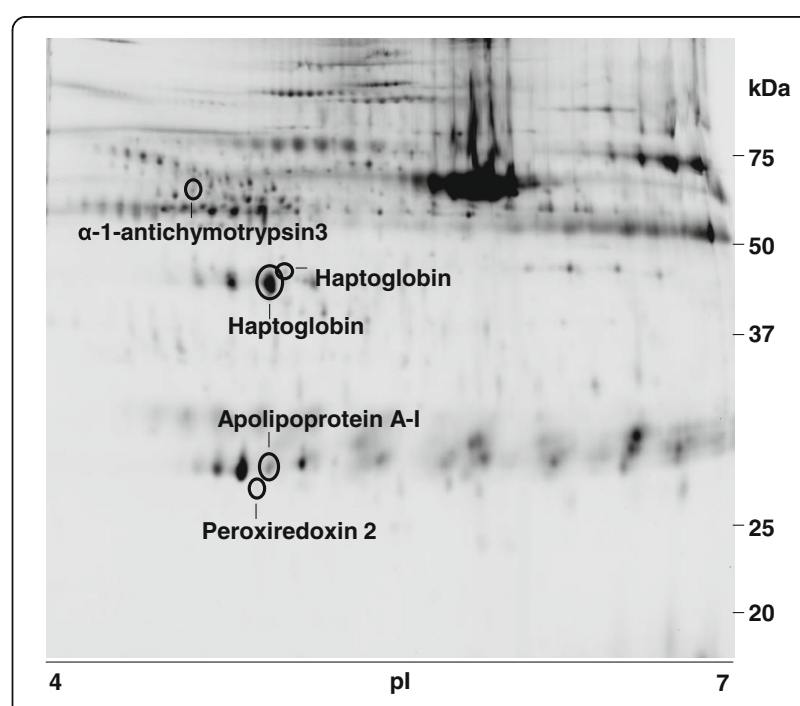

Fig. 3 Serum proteome analysis by DIGE. Representative image of one of the four 2D gels containing $150 \mu \mathrm{g}$ protein $(50 \mu \mathrm{g}$ prot/condition) and stained with Flamingo ${ }^{\oplus}$ (Bio-Rad). Differentially expressed spots identified by MS are marked 
glutathione peroxidase (GPx) isoform 3 (antioxidant defense) were also identified by iTRAQ. Another group of differentially expressed proteins with a relevant function was related to the immune system, including lactotransferrin, protegrin 3 and galectin 1, which increased at D3 in both $\mathrm{H}$ and HS animals, and tended to basal levels at D5. Finally, another relevant protein group were intracellular proteins such as actin-binding proteins, tubulins, enzymes involved in glycolysis and several proteasome subunits, which were found to be increased in serum (Additional file 2). Some of these findings were already observed in the biochemical analysis of all the samples $(n=105)$.

\section{Discussion}

The allocation of sows in isolated farrowing stalls is believed to be a stressful procedure and the change of environmental conditions is a challenge to the individual, that must adapt to the new situation. Several problems and abnormal behaviours have been reported in individualhoused sows, including locomotion difficulties, skin lesions and loss of muscle mass and bone resistance, together with behavioural symptoms $[4-6,10-12]$. In this study, HS gilts were subjected to two parallel stressors, namely individual housing/diet $(\mathrm{H})$ and repeated blood sampling (S) the day before (D1) and at the three following days post stressor (D3, D4 and D5), whereas $\mathrm{H}$ gilts only experienced a switch of housing/diet.

A detailed biochemical profile was performed in all the samples $(n=105)$ and two proteomics approaches were performed for the identification of new potential markers of this stress condition.

All the biochemical parameters analyzed were within the reference range indicating that gilts were healthy during all the days of the experiment. NEFA levels indicated an increase of lipid mobilization from fat stores at D3, whereas the increase of TG at the end of the study in both animal groups indicated that gilts adapted to the new environment and normalized their food intake. Cholesterol was elevated at short-time in the HS group, similarly to high-density housed pigs in our previous study [15]. Variations in lipid metabolism were also observed in the proteomic analyses, as several apolipoproteins involved in lipid transport were found decreased both by iTRAQ and 2D-DIGE studies. These observations confirm that altered lipid metabolism is associated to physiological stress, likely as a consequence of the lipolytic activity of epinephrine and cortisol $[18,19]$.

Stress, change of diet, and low food intake might also have an accelerating effect on tissue protein catabolism, as reflected by urea and creatinine variation. CK, a marker for skeletal muscle, increased in HS gilts probably as a consequence of tissue damage during blood extraction [20]. A strong correlation between CK and ALT was observed $(r=0.785)$, being both enzymes highly abundant in skeletal muscle. The large individual variation in CK and ALT levels suggests that blood sampling was not equally harmful for all the animals.

The measurement of salivary cortisol is recommended due to the simplicity of sampling and direct biological relevance $[21,22]$ and salivary cortisol levels have previously been found to increase in group-housed sows compared with stalled sows [13]. In the present study, serum and salivary cortisol were unaffected, but this latter presented high individual variation, suggesting that the perception of stress was variable between animals $[23,24]$.

Our previous studies in pigs identified Pig-MAP increased by high-density housing, whereas other APP were not altered [15]. In the present situation, $\mathrm{Hp}$ increased and Apo A-I decreased confirming the role of APP as stress markers [25-28]. Pig-MAP concentrations were unexpectedly high at the beginning of the experiment, which could have masked the expected increase of this protein. The high mean value was due to five out of the 15 individuals having a Pig-MAP concentration between 3.0 and $4.5 \mathrm{mg} / \mathrm{mL}$ but with normal values for the other APP, ruling out the possibility of these individuals being ill. Other authors have reported that $\mathrm{Hp}$ and PigMAP behave similar in sows kept in stalls or in group but in that case animals were maintained in the same housing system all time, without changing conditions [29]. On the other hand, CRP profile was remarkably different between the HS and $\mathrm{H}$ groups, suggesting that it may be a good marker of inflammation caused by repeated blood sampling and not affected by housing.

Regarding oxidative stress, gilts of the $\mathrm{H}$ group had higher activity of the antioxidant defence pathways than gilts of the HS group. Repetitive blood sampling might have increased the degree of oxidative stress in the HS gilts by reducing the antioxidant defences or raising the reactive oxygen species (ROS) production [30-32]. These results were similar to our previous studies [15].

Two different proteomic approaches, 2D-DIGE and iTRAQ, revealed larger variations in protein composition in the HS group than in the $\mathrm{H}$ group, confirming that gilts repeatedly sampled and subjected to the change of housing/diet were exposed to a stronger challenge than gilts only subjected to this latter situation. Working with pooled samples has some limitations as it can reduce the effects of biological variation. Nevertheless, pooling does not mask the biological variation itself and it has been shown to be beneficial when working with a high number of individuals [33, 34].

Only two proteins, Apo A-I and PRDX2, were identified as differential proteins in both procedures, probably as a consequence of the complementary nature of the two techniques [35], the lower fold-changes achieved by 
iTRAQ [36] and the use of different serum proteomes (raw serum and serum enriched in low- and mediumabundance proteins, respectively). Nevertheless, both methods confirmed the innate immune system and the redox defence pathways as the two main homeostatic mechanisms involved in the stress response. Thus, Hp increased after the housing switch, confirming previous results. Other altered proteins related to the immune defences were $\alpha 1$-antichymotrypsin 3 , lactotransferrin, ficolin-2, protegrin 3 and galectin 1. Protegrins are short cathelicidins exclusively produced by leukocytes [37], which are upregulated by proinflammatory cytokines and APPs, and may be proposed as indicators of the innate immune response in the pig $[38,39]$. The immune profile of sows housed in stalls is different from those housed in a greater floor space [40,41], and it has been suggested that it may reflect a physiological stress response that enabled them to adapt to their environment. All together, these results suggest that an immunological response is required to reestablish homeostasis.

The involvement of oxidative processes was also confirmed by proteomics, since several antioxidant enzymes were found differentially expressed i.e. PRDX2 increased, whereas GPx isoform 3 (plasma isoform) decreased. GPx activity was found increased in erythrocyte lysates, but the involvement of different GPx isoforms could explain the apparent contradiction between iTRAQ and enzymatic results.

Proteomics also indicated that a certain degree of cellular damage has occurred, entailing a relative increase of cellular proteins in plasma, such as actin-binding proteins, tubulins, enzymes involved in glycolysis and several proteasome subunits. Some of these proteins are potentially good markers, since their increase in serum is large. This is the case of tropomyosin-beta, glycogen phosphorylase and glyceraldehyde-3-phosphate dehydrogenase (Additional file 2). Cellular leakage could be increased due to physical injuries linked to the reduced space of the individual stall and to sample extraction. It is interesting to note that the cytoplasmatic protein $\beta$ actin has been previously validated as a stress biomarker in pigs housed at a high density [15]. Nevertheless, a thorough validation of these proteins in a higher number of individuals and in different stress conditions should be performed before they could be considered adequate biomarkers.

In all the cases (biochemical markers and proteomics results) the serum analytical variations observed in the $\mathrm{H}$ and $\mathrm{HS}$ group took place in the same direction. Global changes were always larger in the HS than in the H group, reinforcing the idea that damage was more important in gilts subjected to both types of stressors.

Further research is needed to confirm the potential role of the differentially expressed proteins as stress biomarkers and to characterize their specificity, sensitivity and kinetics.

\section{Conclusions}

The confinement of gilts in individual stalls promotes relevant changes in serum composition including an increase of lipid, protein catabolism and oxidative stress, the activation of the innate immune system and may cause tissue damage. Therefore we propose that a combination of plasma lipid markers, APP or other innate immune indicators, redox components, intracellular proteins and salivary cortisol may be proposed as a welfare laboratory profile for its application in the pig routine.

\section{Additional files}

\begin{abstract}
Additional file 1: Experimental design of the 2D-DIGE experiment (word file). The pooled D1 sample was labelled with Cy2 and used as internal standard in all four gels. Dye-swap was performed and samples were randomly paired. (DOCX $12 \mathrm{~kb})$

Additional file 2: Complete list of differentially expressed proteins identified by DIGE at D3 and D5 versus D1 (basal conditions) in $\mathrm{H}$ and HS groups (XLS file). Increased proteins at D3 are represented as positive foldchanges (FC) and decreased proteins as negative FC. Proteins are ordered by number of spot. (DOCX $16 \mathrm{~kb}$ )

Additional file 3: List of differentially expressed proteins identified and quantified by ITRAQ at D3 and D5 versus D1 (basal conditions) in $\mathrm{H}$ and HS groups (XLS file). Increased proteins at D3 are represented as positive fold-changes (FC) and decreased proteins as negative FC. Proteins are classified according to their biological function and ordered by Mascot score. (DOCX $41 \mathrm{~kb})$
\end{abstract}

\section{Abbreviations}

2D: Bidimensional electrophoresis; ALP: Alkaline phosphatase; ALT: Alanine aminotransferase; Apo A-I: Apolipoprotein A-l; APP: Acute phase protein;

CK: Creatine kinase; CRP: C-reactive protein; DIGE: Differential gel electrophoresis; FC: fold change; GPx: Glutathione peroxidase; Hp: Haptoglobin; iTRAQ: Isobaric tag for relative and absolute quantitation; MS: Mass spectrometry; NEFA: Non-esterified fatty acids; Pig-MAP: Pig major acute phase protein; PRDX2: Peroxiredoxin 2; ROS: Reactive oxygen species; SOD: Superoxide dismutase; TG: Triglycerides; tGSH: Total glutathione

\section{Acknowledgements}

The authors thank Mrs. A. Vilalta and Mr. J. Serra for their excellent technical assistance at laboratory and farm level, respectively, and Mr. S. Bernaus and Mr R. Serra to allow us carrying out in vivo experiments in their swine facilities. We are grateful to Dr. F. Canals, Dr. J.J. Bech-Serra and Dr. C. de la Torre (Servei de Proteòmica, Institut de Recerca Vall d'Hebron, Barcelona, Spain) and Dr. E. de Oliveira (Servei de Proteòmica, Parc Científic de Barcelona, Barcelona, Spain) for their help with proteomic analysis. We also thank Dr. F. Lampreave (University of Zaragoza, Spain) for providing the anti-ApoA-I antibody.

\section{Funding}

This work was supported by grant AGL2011-30598-C03-02 from the Spanish Ministerio de Ciencia y Innovación and grant 2009SGR-1091 from the Generalitat de Catalunya (AB). Part of the funding was financed by the FEDER program from the European Union. AMR was supported by a fellowship from the Spanish Ministerio de Educación and a Short Term Scientific Mission grant from the COST Action FA1002 (Farm Animal Proteomics).

\section{Availability of data and materials}

The dataset supporting the conclusions of this article is provided in two XLS files (see Additional files 2 and 3). 


\section{Authors' contributions}

$A B$ and LF conceived and designed the study. AMR and LA performed the experiments. RP, RP and YS performed the biochemical analysis. EB supervised the iTRAQ data analysis and revised the manuscript. $A B$ and $A M R$ analyzed the results. $A B, A M R$ and $L F$ wrote the manuscript. All authors read and approved the final manuscript

\section{Competing interests}

The authors declare that they have no competing interests.

\section{Consent for publication}

Not applicable.

\section{Ethics approval and consent to participate}

Treatment, housing and husbandry conditions conformed to the European Union Guidelines (The Council of the European Communities 1986 and directive 2010/63/EU, where applicable). The experiment received approval from the Ethical Committee for Animal Experimentation from the Universitat de Lleida (DAAM7684)

The owner of the animals has received the necessary information about the study and he has agreed to participate in this investigation. A letter with the informed consent of the owner of the animals is available.

\section{Author details}

1Departament de Bioquímica i Biologia Molecular, Facultat de Veterinària, Universitat Autònoma de Barcelona, Cerdanyola del Vallès 08193, Spain. ${ }^{2}$ Servei de Bioquímica Clínica Veterinària, Facultat de Veterinària, Universitat Autònoma de Barcelona, Cerdanyola del Vallès 08193, Spain. ${ }^{3}$ Departament de Ciencia Animal, Universitat de Lleida, 25198 Lleida, Spain. ${ }^{4}$ Agrotecnio Center, Lleida, Spain. ${ }^{5}$ Department of Molecular Biology and Genetics, Aarhus University, Aarhus C 8000, Denmark. ${ }^{6}$ Present Address: Departament de Nutrició, Ciències de l'Alimentació i Gastronomia, Facultat de Farmàcia Ciències de l'Alimentació, Universitat de Barcelona, Barcelona 08028, Spain.

\section{Received: 25 August 2015 Accepted: 17 November 2016}

\section{Published online: 25 November 2016}

\section{References}

1. Bracke MBM, Metz JHM, Spruijt BM, Schouten WGP. Decision support system for overall welfare assessment in pregnant sows B: validation by expert opinion. J Anim Sci. 2002;80:1835-45.

2. Curtis SE, Hurst RJ. The physical space requirement of the sow. J Anim Sci. 1989;67:1242-8.

3. McGlone JJ, Vines B, Rudine AC, DuBois P. The physical size of gestating sows. J Anim Sci. 2004;82:2421-7

4. Karlen GAM, Hemsworth PH. The welfare of gestating sows in conventiona stalls and large groups on deep litter. Appl Anim Behav Sci. 2007;105:87-101.

5. Marchant JN, Broom DM. Effects of dry sow housing conditions on muscle weight and bone strength. Anim Sci. 1996;62:105-13.

6. Salak-Johnson JL, Niekamp SR, Rodriguez-Zas SL, Ellis M, Curtis SE. Space allowance for dry, pregnant sows in pens: body condition, skin lesions, and performance. J Anim Sci. 2007;85:1758-69.

7. Barnett JL, Hemsworth PH, Winfield CG. The effects of design of individual stalls on the social behaviour and physiological responses related to the welfare of pregnant pigs. Appl Anim Behav Sci. 1987;18:133-42.

8. England DC, Spurr DT. Litter size of swine confined during gestation. J Anim Sci. 1969:28:220-9.

9. Schmidt WE, Stevenson JS, Davis DL. Reproductive traits of sows penned individually or in groups until 35 days after breeding. J Anim Sci. 1985;60:755-9.

10. Vieuille-Thomas C, Le Pape G, Signoret J. Stereotypies in pregnant sows: indications of influence of the housing system on the patterns expressed by the animals. Appl Anim Behav Sci. 1995;44:19-27.

11. Conte S, Bergeron R, Grégoire J, Gète M, D'Allaire S, Meunier-Salaün M-C, et al. On-farm evaluation of methods to assess welfare of gestating sows. Animal. 2014;8:1153-61.

12. Chapinal N, Ruiz de la Torre JL, Cerisuelo A, Gasa J, Baucells MD, Coma J, et al. Evaluation of welfare and productivity in pregnant sows kept in stalls or in 2 different group housing systems. J Vet Behav Clin Appl Res. 2010:5:82-93.

13. Zhou Q, Sun Q, Wang G, Zhou B, Lu M, Marchant-Forde JN, et al. Group housing during gestation affects the behaviour of sows and the physiological indices of offspring at weaning. Animal. 2014;8:1162-9.
14. Fraser D, Duncan IJH, Edwards SA, Grandin T, Gregory NG, Guyonnet V, et al General principles for the welfare of animals in production systems: the underlying science and its application. Vet J. 2013;198:19-27.

15. Marco-Ramell A, Pato R, Pena R, Saco Y, Manteca X, Ruiz de la Torre JL, et al. Identification of serum stress biomarkers in pigs housed at different stocking densities. Vet J. 2011:190:e66-71.

16. Marco-Ramell A, Arroyo L, Saco Y, Garcia-Heredia A, Camps J, Fina M, et al. Proteomic analysis reveals oxidative stress response as the main adaptative physiological mechanism in cows under different production systems. J Proteomics. 2012;75:4399-411.

17. Wiese S, Reidegeld KA, Meyer HE, Warscheid B. Protein labeling by iTRAQ: a new tool for quantitative mass spectrometry in proteome research. Proteomics. 2007:7:340-50.

18. Alwaili K, Bailey D, Awan Z, Bailey SD, Ruel I, Hafiane A, et al. The HDL proteome in acute coronary syndromes shifts to an inflammatory profile. Biochim Biophys Acta. 1821;2012:405-15.

19. Black PH. Stress and the inflammatory response: a review of neurogenic inflammation. Brain Behav Immun. 2002;16:622-53.

20. Kramer JW, Hoffmann WE. Clinical Enzimology. In: Kaneko JJ, Harvey JW, Bruss ML, editors. Clin. Biochem. Domest. Anim. 5th ed. San Diego: Academic; 1997. p. 303-25.

21. Mormede P, Andanson S, Auperin B, Beerda B, Guemene D, Malmkvist J, et al. Exploration of the hypothalamic-pituitary-adrenal function as a tool to evaluate animal welfare. Physiol Behav Neurogenetics and Stress. 2007;92:317-39.

22. Bushong DM, Friend TH, Knabe DA. Salivary and plasma cortisol response to adrenocorticotropin administration in pigs. Lab Anim. 2000;34:171-81.

23. Hennessy DP, Stelmasiak T, Johnston NE, Jackson PN, Outch KH. Consistent capacity for adrenocortical response to ACTH administration in pigs. Am J Vet Res. 1988;49:1276-83

24. Ponsuksili S, Du Y, Murani E, Schwerin M, Wimmers K. Elucidating molecular networks that either affect or respond to plasma cortisol concentration in target tissues of liver and muscle. Genetics. 2012;192:1109-22.

25. Horadagoda NU, Knox KM, Gibbs HA, Reid SW, Horadagoda A, Edwards SE, et al. Acute phase proteins in cattle: discrimination between acute and chronic inflammation. Vet Rec. 1999;144:437-41.

26. Eckersall PD, Bell R. Acute phase proteins: Biomarkers of infection and inflammation in veterinary medicine. Vet J. 2010;185:23-7.

27. Giannetto C, Marafioti S, Fazio F, Piccione G, Giudice E, Casella S. Acute phase protein response during road transportation and lairage at a slaughterhouse in feedlot beef cattle. J Vet Med Sci. 2011;73:1531-4.

28. Heegaard PM, Stockmarr A, Pineiro M, Carpintero R, Lampreave F, Campbell FM, et al. Optimal combinations of acute phase proteins for detecting infectious disease in pigs. Vet Res. 2011;42:50.

29. Sorrells AD, Eicher SD, Harris MJ, Pajor EA, Richert BT. Periparturient cortisol, acute phase cytokine, and acute phase protein profiles of gilts housed in groups or stalls during gestation. J Anim Sci. 2007;85:1750-7.

30. Lykkesfeldt J, Svendsen O. Oxidants and antioxidants in disease: oxidative stress in farm animals. Vet J. 2007;173:502-11.

31. Costantini D, Marasco V, Møller AP. A meta-analysis of glucocorticoids as modulators of oxidative stress in vertebrates. J Comp Physiol B. 2011;181:447-56.

32. Dahlgren C, Karlsson A, Bylund J. Measurement of respiratory burst products generated by professional phagocytes. Methods Mol Biol. 2007;412:349-63.

33. Zhang S-D, Gant TW. Effect of pooling samples on the efficiency of comparative studies using microarrays. Bioinformatics. 2005;21:4378-83.

34. Kendziorski C, Irizarry RA, Chen K-S, Haag JD, Gould MN. On the utility of pooling biological samples in microarray experiments. Proc Natl Acad Sci U S A. 2005;102:4252-7.

35. Wu WW, Wang G, Baek SJ, Shen R-F. Comparative study of three proteomic quantitative methods, DIGE, CICAT, and iTRAQ, using 2D gel- or LC-MALDI TOF/TOF. J Proteome Res. 2006;5:651-8.

36. Ow SY, Salim M, Noirel J, Evans C, Rehman I, Wright PC. iTRAQ underestimation in simple and complex mixtures: "the good, the bad and the ugly.". J Proteome Res. 2009;8:5347-55.

37. Kokryakov VN, Harwig SS, Panyutich EA, Shevchenko AA, Aleshina GM, Shamova OV, et al. Protegrins: leukocyte antimicrobial peptides that combine features of corticostatic defensins and tachyplesins. FEBS Lett. 1993;327:231-6.

38. Wu H, Zhang G, Minton JE, Ross CR, Blecha F. Regulation of cathelicidin gene expression: induction by lipopolysaccharide, interleukin-6, retinoic acid, and Salmonella enterica serovar typhimurium infection. Infect Immun. 2000;68:5552-8 
39. Wang $Y$, Shan $T, X u Z$, Liu J, Feng J. Effect of lactoferrin on the growth performance, intestinal morphology, and expression of PR-39 and protegrin1 genes in weaned piglets. J Anim Sci. 2006;84:2636-41.

40. Salak-Johnson JL, DeDecker AE, Horsman MJ, Rodriguez-Zas SL. Space allowance for gestating sows in pens: behavior and immunity. J Anim Sci. 2012;90:3232-42.

41. Grün V, Schmucker S, Schalk C, Flauger B, Stefanski V. Characterization of the adaptive immune response following immunization in pregnant sows (Sus scrofa) kept in two different housing systems. J Anim Sci. 2014;92: 3388-97.

42. Yolanda Saco, Lorenzo Fraile, Mercè Giménez, Francesca Canalias and Anna Bassols. Validation of an immunoturbidimetric method for determination of porcine serum C-reactive protein. Res Vet Sci. 2010;89: 159-162

Submit your next manuscript to BioMed Central and we will help you at every step:

- We accept pre-submission inquiries

- Our selector tool helps you to find the most relevant journal

- We provide round the clock customer support

- Convenient online submission

- Thorough peer review

- Inclusion in PubMed and all major indexing services

- Maximum visibility for your research

Submit your manuscript at www.biomedcentral.com/submit
Biomed Central 